\title{
Brachial Plexus Injury Surgical Service in Time of Coronavirus Disease 2019 Pandemic Experience from a Single Tertiary Orthopaedic Hospital in Indonesia
}

\author{
Seti Aji Hadinoto ${ }^{1,2 *}\left(\mathbb{D}\right.$, Tito Sumarwoto ${ }^{1,2}$, Mohammad Erstda Trapsilantya ${ }^{1}$ \\ ${ }^{1}$ Department of Orthopaedic and Traumatology, Sebelas Maret University, Surakarta, Indonesia; ${ }^{2}$ Department of Orthopaedic and \\ Traumatology, Division of Upper Limb and Microreconstruction, Prof. Dr. R. Soeharso Orthopaedic Hospital, Surakarta, Indonesia
}

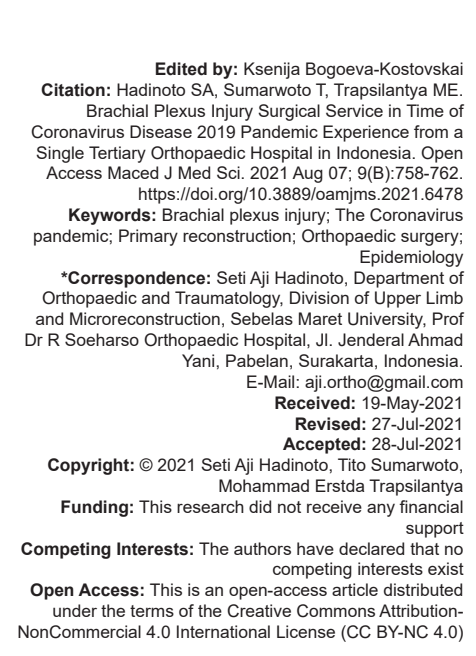

\section{Introduction}

Brachial plexus injury (BPI) is an injury to the peripheral nervous system, namely the brachial plexus, which is one of the most severe nerve injuries to the extremities [1], [2], [3], [4]. The classifications that are often used are upper type, lower type, and whole or panplexal. BPI in adults is an increasingly common clinical problem. Injury patterns, timing of surgery, priority on recovery of function, and patients's understanding about the expectations of the prognosis are things that are important to consider before deciding on surgical management. There are several options for treatment such as neurolysis, nerve grafting, or nerve transfers and should be done before 6 months after the injury [5], [6]. Meanwhile, the management of using free functioning muscle transfers can improve the function in an acute or late condition [9], [10], [11], [12], [13].

Coronavirus disease 2019 (COVID-19) pandemic has significantly affect all medical sectors [9]. Surgery practice is one of the impacted sectors, both in medical personel safety and patient perception on hospital care procedure, such as mandatory perioperative polymerase chain reaction (PCR) swabs test for elective surgery. In addition, the operating procedures carried out by operators are also different when compared to before the pandemic, all aimed at maintaining medical personel and patient's safety in the pandemic era. Surgical practitioners should use personal protective equipment (PPE) such as protective suit, face shield, google, fluid resist shoes cover, and medical mask during surgery. The pandemic also has 
consequences on work methods, surgical technique, open versus minimally invasive procedure, surgical theater workflow, patient and staff safety, training, and education [1].

\section{Materials and Methods}

This is a retrospective descriptive study of patients who underwent surgery for BPI before and during the pandemic of COVID-19. Data was collected from March 1, 2019 until December 31, 2020 at Prof. Dr. Soeharso Orthopedic Hospital, Surakarta, Indonesia. The year of 2019 was assigned as period before pandemic and the year of 2020 was assigned as period during pandemic. All emergency and elective surgeries during this period were included in the study. We collect the demographic data, total number of surgery, type of BPI, type of surgery performed, and patients' area of origin. At admission, all patients reported upper extremities weakness or pain as the chief complain. All patients were diagnosed with BPI and had complete entry data, such as age, gender, time of injury, and therapy given. We also performed statistical analyses with significance level of 0.05 .

There were two active hand surgeons in our hospital: 1 senior hand surgeon and 1 junior hand surgeon. Both of the surgeons were aged $<60$ years old.

\section{Results}

Based on historical data of patients treated for BPI at Prof. Dr. Soeharso Orthopedic Hospital, we found a total of 51 cases of BPI in 2019 and 43 cases in 2020. The data in Figure 1 shown there was slight fluctuation each month. However, even on the pandemic, there was no significant difference on quantity of BPI operation even when pandemic started December 2019 until today.

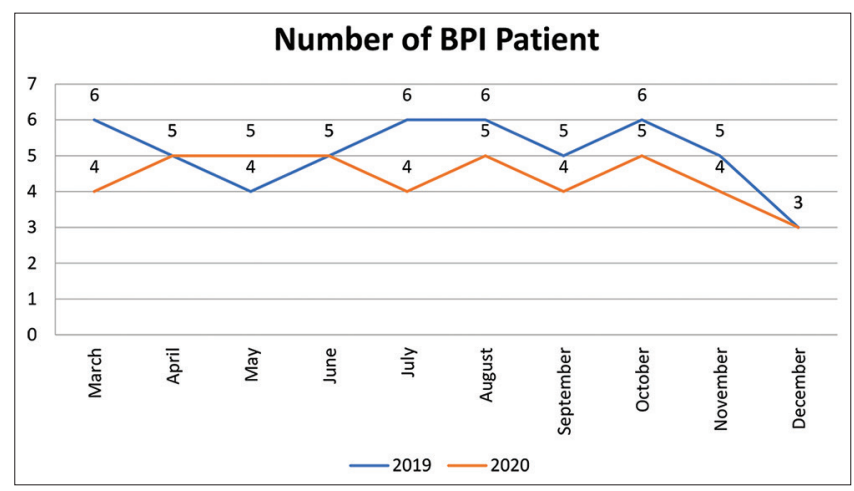

Figure 1: Comparison data of brachial plexus injury patients before and during COVID-19 pandemic
The data shown in Figure 2 represents the diagram of BPI patients based on age and sex. We found 39 male patients (72\%) in 2019 and 38 male patients $(88 \%)$ in 2020 . The majority of patients in 2019 and 2020 came from the 15-44 years old age group, with 33 patients $(66 \%)$ and 36 patients (84\%), respectively. We performed statistical analyses using Chi-square and Multinomial Logistic Regression to compare the difference of BPI patients based on sex and age, respectively. From both Chi-square and Multinomial Logistic Regression analyses, we found that there was no significant difference in BPI patients based on sex and age in the period of before and during the COVID-19 pandemic ( $p=0.506$ and 0.55 , respectively).

Based on the division of BPI type, we found 27 and 20 panplexal injury patients in 2019 and 2020, respectively. In the upper plexus injury group, we found 24 patients in the period before pandemic and 23 patients in the period during pandemic. We found no patient with lower plexus injury in both 2019 and 2020. We performed Chi-square analysis to compare the amount of BPI patients based on injury type before and during the COVID-19 pandemic and found no statistically significant difference $(p=0.509)$. The data of BPI patients based on injury type can be seen in Figure 3 .

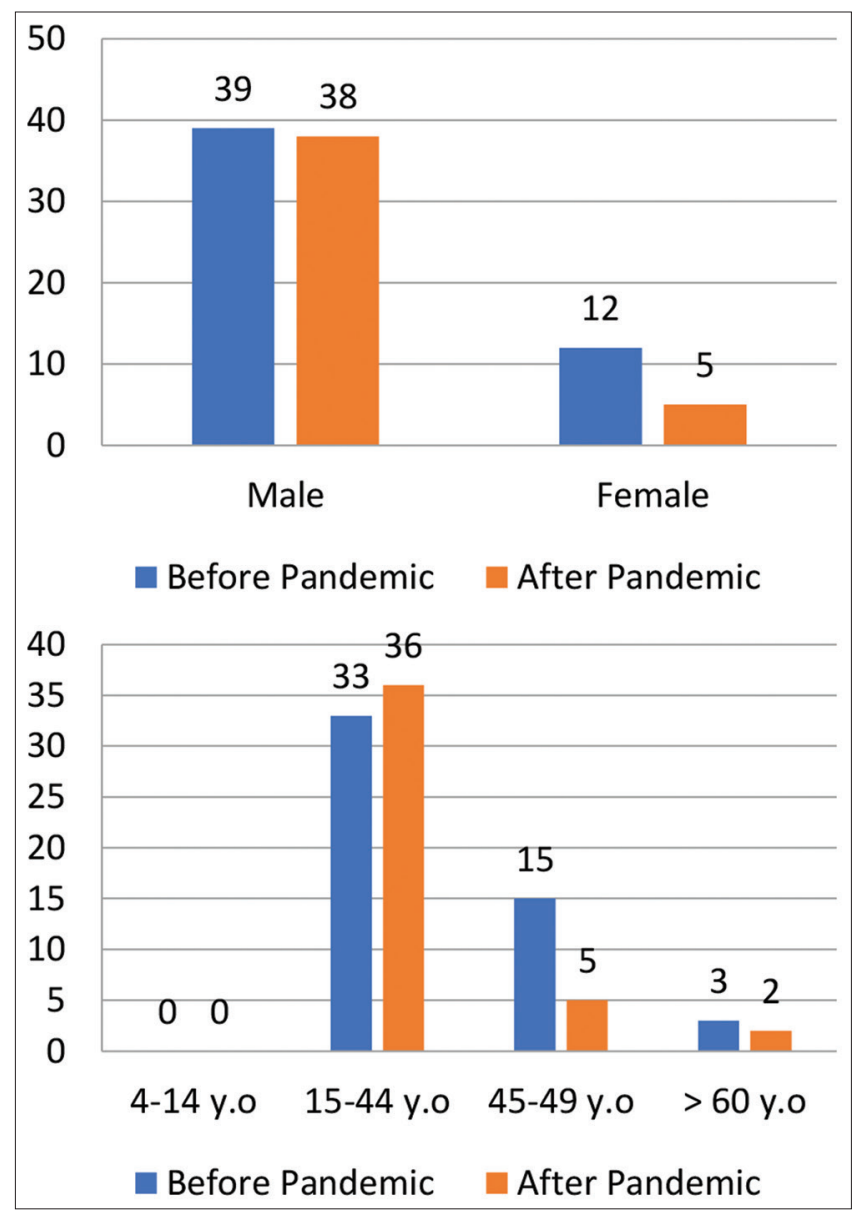

Figure 2: Diagrams of brachial plexus injury patients based on age and gender before and during pandemic 


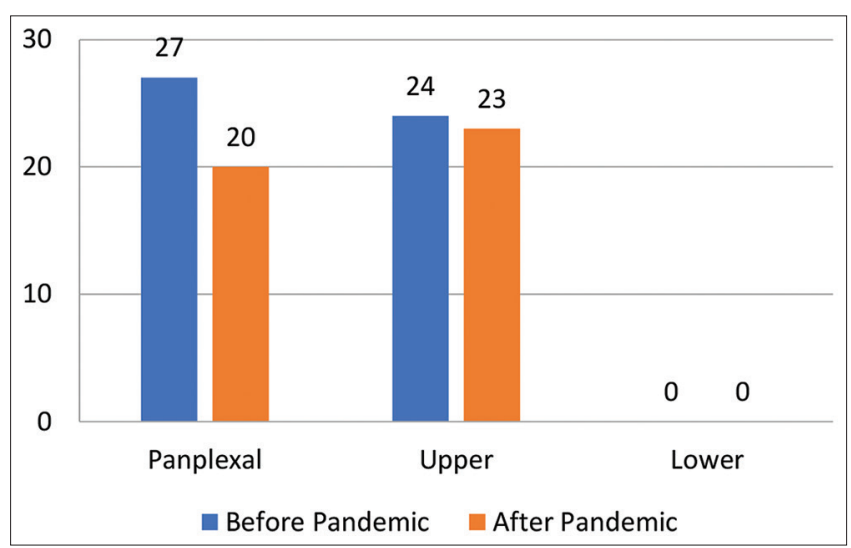

Figure 3: Diagram of brachial plexus injury patients based on injury type

We also collected the data of the type of surgery performed on $\mathrm{BPI}$ patients, namely, primary reconstruction and secondary reconstruction. Before the pandemic, there were $26(51 \%)$ primary reconstruction and $25(49 \%)$ secondary reconstruction surgeries performed. After the pandemic started, there were $25(59 \%)$ primary reconstruction and $18(41 \%)$ secondary reconstruction surgeries. From the Chi-square analysis performed to compare the amount of BPI patients based on the type of surgery performed before and during the pandemic, we found that there was no statistically significant difference $(p=0.546)$. The data for type of surgery is represented in Figure 4.

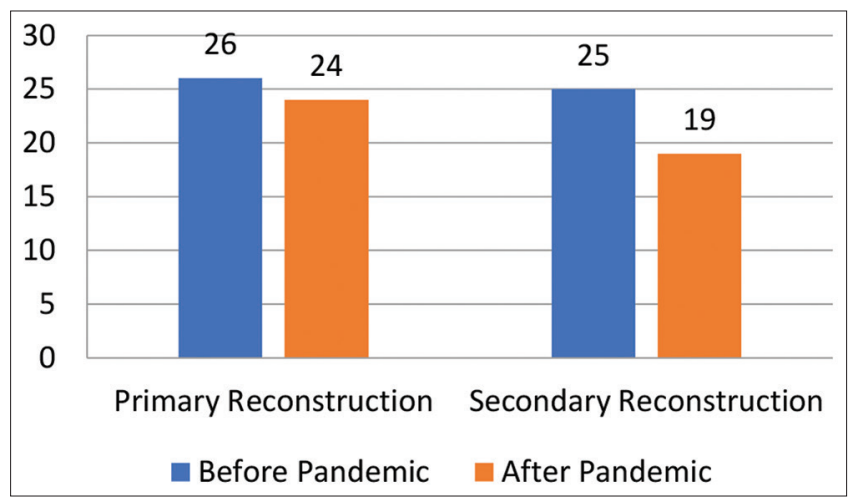

Figure 4: Diagram of brachial plexus injury patients based on surgery performed before and after pandemic

Finally, we also analyzed the data of patients' area of origin. We categorized the patients in two groups: from Surakarta (Solo) city and from outside of Solo city. The amount of patients in the from Solo group was constant; $6(11 \%)$ patients in the period before pandemic and $5(11 \%)$ patients in the period after pandemic. Based on Figure 5, we found the amounts of patients from outside of Solo to be $45(90 \%)$ and $38(89 \%)$ in 2019 and 2020, respectively. Based on the Chi-square analysis we performed, we found that there was no significant difference of the amount of BPI patients based on patients' area of origin in the period of before and during the COVID-19 pandemic $(p=0.801)$.

\section{Discussion}

BPIs would cause a significant decreased quality of life [3]. Patients with an upper arm type BPI, meaning C5 and C6 root injuries, would lose shoulder elevation/external rotation, and elbow flexion function. Additional elbow, wrist, and hand extension function deficits would occur in patients with $\mathrm{C} 7$ root injury. Let alone with total type C5-T1 (panplexal), the patients will lose all of the upper extremity function [11]. With the advancement of reconstructive surgical procedure and better equipment, BPI could be successfully treated through various methods such as neurolysis, nerve grafting, nerve transfer, muscle/tendon transfer, and free functioning muscle transfer to restore the shoulder, arm, and hand function.

Early plexus reconstruction $\leq 3$ months) offers the best functional results and reduces the need for secondary reconstructions [10], [15]. Two main treatment strategies have been used: primary surgery consists of the exploration and reconstruction of the affected part of the brachial plexus, and secondary procedures that include tendon or muscle transfer, ost€eotomy, and other orthopedic techniques. Secondary procedures can be performed as the only surgical treatment on late obstetrical palsy or after failed primary surgery, to minimize defects [14], [16].

In the data obtained from patients treated or undergoing BPI surgery at Prof. Soeharso Orthopedic Hospital before (2019) and during the COVID-19 pandemic (2020) with similar ratio of the number of months, there were 51 cases before the pandemic and 43 cases after the pandemic. Based on the panplexal type of BPI before the pandemic there were 27 patients, and during the pandemic 20 patients, the upper type before: during the pandemic was 24: 23 , and 0 lower type cases. From this data, it could be concluded that there is no significant difference in the level of visits or surgeries of brachial plexus surgery at our hospital. This could be caused by various things, one of which is the level of patient confidence in the health protocols that is implemented in our hospital, and the understanding of the patient about the prognosis of their injury.

The procedure of health protocol in our hospital is to do pre-operative screening at outpatient clinic to all patients who will undergo BPI surgery include: history and clinical examination, laboratory examination, chest radiograph, rapid COVID-19 test and PCR swab test 24 hours before surgery as suggested by Muharraqi et al, 2020 [2]. We implemented social distancing protocol for 


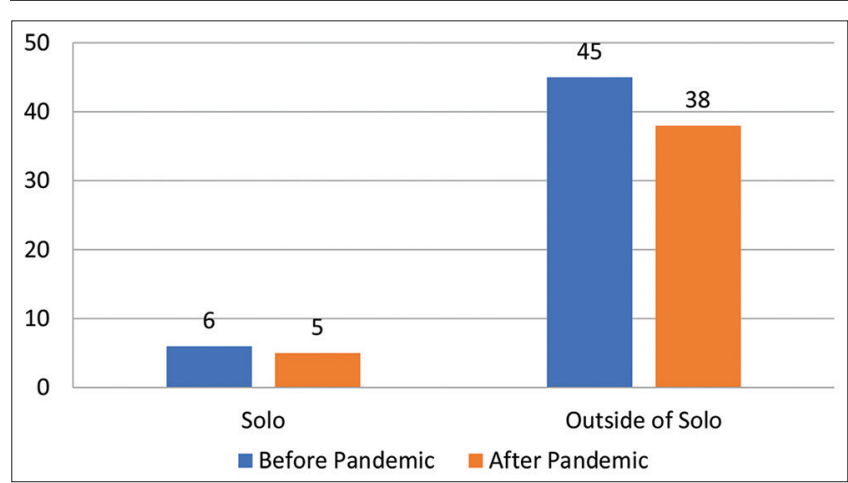

Figure 5: Diagram of brachial plexus injury patients based on patients area of origin

patient and hospital staff, by modifying the waiting seats, policlinic room and relying more to technology, such as telemedicine and online registration. Our hospital also required everyone including patient and hospital staff to wear a minimum of one layer of surgical mask during their stay in hospital. This protocol is expected to reduce the risk of contracting COVID-19 as described by Telles et al. [17]. Decision to proceed elective surgery was performed by internist at our institution. Patients with confirmed COVID-19 based on PCR swab were referred to special referral hospital of COVID-19 in our area for further care. We also use complete PPE for the medical personnel when performing the operation, such as whole-body cover protective suit, face shield, google, fluid resist shoes cover, and a double layer medical mask (N95 mask and surgical mask). The recommendations mentioned above are carried out to reduce risks for patients, staff, and the community. Our hospital also performs routine PCR swab test for medical personnel for COVID-19 screening.

The main reason for continuing surgery in midst of the pandemic includes trust in the hospital system and their condition which was considered severe by patients. It is important to address patient concerns with appropriate patient education and interim procedures when planning elective orthopedic surgery during a pandemic [7].

Important things to note for the purposes of surgical management include injury patterns, timing of surgery, priorities on function recovery, and patient's understanding about the expectations of prognosis [12]. Of these interests, the other data we collect is about the time of surgery. Primary reconstruction done before pandemic was 28 patients, and during pandemic is 30 patients. And secondary reconstruction done before the pandemic is 20 patients, while during the pandemic there are 16 patients. The success of BPI surgery is strongly influenced by the time of surgery, therefore, we continue to perform primary reconstruction surgery with strict health protocols as mentioned above. Even though the Indonesian government implemented a local lockdown in Sukoharjo and Surakarta city, with restrictions on community activities, closing workplaces, eliminating car-free days, and regional quarantine of new arrivals [8], but we found there is no significant difference about the origin of patient during lockdown in Sukoharjo and Surakarta, mostly because patients from out of town are still free to enter Sukoharjo and Surakarta for medical treatment as long as they bring a letter of explanation from our hospital.

There were limitation in this study. This was a descriptive retrospective study which may has its own weakness. The period of the evaluation was 10 months period, which could not describe the whole duration of pandemic. However this study, we believe could give some picture of COVID-19 pandemic effect for BPI Surgery in our institution, especially in early period.

\section{Conclusion}

COVID-19 pandemic has no significant effect in the term of number and time of BPI surgery performed. Better outcome in BPI surgery is influenced by the timing of the operation, therefore primary reconstruction remains the main choice for BPI patients with safety concern or health protocols.

\section{References}

1. Al-Jabir A, Kerwan A, Nicola M, Alsafi Z, Khan M, Sohrabi C, et al. Impact of the Coronavirus (COVID-19) pandemic on surgical practice-Part 2 (surgical prioritisation). Int J Surg. 2020;79:233-48. https://doi.org/10.1016/j.ijsu.2020.05.002 PMid:32407799

2. Al-Muharraqi MA. Testing recommendation for COVID-19 (SARS-CoV-2) in patients planned for surgery-continuing the service and 'suppressing' the pandemic. $\mathrm{Br} \mathrm{J}$ Oral Maxillofac Surg. 2020;58(5):503-5. https://doi.org/10.1016/j. bjoms.2020.04.014

PMid:32307131

3. Caranci F, Briganti F, la Porta M, Antinolfi G, Cesarano E, Fonio $\mathrm{P}$, et al. Magnetic resonance imaging in brachial plexus injury. Musculoskelet Surg. 2013;97 Suppl 2:S181-90. https:// doi.org/10.1007/s12306-013-0281-0

PMid:23949940

4. Recommendations for patients with complex nerve injuries during the COVID-19 pandemic. Can J Neurol Sci. 2021;48:50-5. PMid:32847634

5. Hoang D, Chen VW, Seruya M. Recovery of elbow flexion after nerve reconstruction versus free functional muscle transfer for late, traumatic brachial plexus palsy: A systematic review. Plast Reconstr Surg. 2018;141(4):949-59. https://doi.org/10.1097/ prs. 0000000000004229 PMid:29595730

6. Hsueh YH, Tu YK. Surgical reconstructions for adult brachial plexus injuries. Part I: Treatments for combined C5 and C6 
injuries, with or without C7 injuries. Injury. 2020;51(4):787-803. https://doi.org/10.1016/j.injury.2020.02.076

PMid:32156416

7. Ho SWL, Tan TL, Lee KT. Elective orthopaedic surgery and COVID-19: Knowledge and perceptions of patients in a global pandemic. Singapore Med J. 2020;1-12. https://doi. org/10.11622/smedj.2020109

PMid:32668869

8. Keputusan Menteri Kesehatan Republik Indonesia Nomor hk.01.07/Menkes/413/2020 Tentang Pedoman Pencegahan Dan Pengendalian, 2020; 2019.

9. Lu R, Zhao X, Li J, Niu P, Yang B, Wu H, et al. Genomic characterisation and epidemiology of 2019 novel Coronavirus: Implications for virus origins and receptor binding. Lancet. 2020;395(10224):565-74.

PMid:32007145

10. Martin E, Senders JT, DiRisio AC, Smith TR, Broekman ML. Timing of surgery in traumatic brachial plexus injury: A systematic review. J Neurosurg. 2018;2018:1-13. https://doi. org/10.3171/2018.1.jns172068

PMid:29999446

11. Miller C, O'Sullivan J, Jeffrey J, Power D. Brachial plexus neuropathies during the COVID-19 pandemic: A retrospective case series of 15 patients in critical care. Phys Ther. 2021;101(1):pzaa191. https://doi.org/10.1093/ptj/pzaa191 PMid:33395478

12. Jessop ZM, Dobbs TD, Ali SR, Combellack E, Clancy R, Ibrahim N, et al. Personal protective equipment for surgeons during COVID-19 pandemic: Systematic review of availability, usage and rationing $\mathrm{Br} J$ Surg. 2020;107:1262-80. https://doi. org/10.1002/bjs. 11750
PMid:32395837

13. Noland SS, Bishop AT, Spinner RJ, Shin AY. Adult traumatic brachial plexus injuries. J Am Acad Orthop Surg. 2019;27(19):705-16.

PMid:30707114

14. Ogliari G, Lunt E, Ong T, Marshall L, Sahota O. The impact of lockdown during the COVID-19 pandemic on osteoporotic fragility fractures: An observational study. Arch Osteoporos. 2020;15(1):156. https://doi.org/10.1007/s11657-020-00825-1 PMid:33026586

15. Socolovsky M, Costales JR, Paez MD, Nizzo G, Valbuena S, Varone E. Obstetric brachial plexus palsy: Reviewing the literature comparing the results of primary versus secondary surgery. Childs Nerv Syst. 2016;32(3):415-25. https://doi. org/10.1007/s00381-015-2971-4 PMid:26615411

16. Terzis JK, Kokkalis ZT. Primary and secondary shoulder reconstruction in obstetric brachial plexus palsy. Injury. 2008;39 Suppl 3:S5-14. https://doi.org/10.1016/j. injury.2008.06.001

PMid:18684457

17. Telles CR, Roy A, Ajmal MR, Mustafa SK, Ahmad MA, de la Serna JM, et al. The impact of COVID-19 management policies tailored to airborne SARS-CoV-2 transmission: Policy analysis. JMIR Public Health Surveill. 2021;7(4):e20699. https://doi. org/10.2196/20699

PMid:33729168

18. Leonard S, Woehrle T, Nikizad H, VearrierJ, Odean M, Renier C, et al. Blunt traumatic brachial plexus injuries in a northern rural US setting: Increased likelihood in unshielded motor-powered crashes. Trauma Surg Acute Care Open. 2020;5:e00058. 